\title{
Sakubitril/valsartan yaşam kalitesini ne kadar değiştirir?
}

\author{
Dr. Fahriye Vatansever Ağca
}

Sağlık Bilimleri Üniversitesi, Bursa Yüksek İhtisas Eğitim ve Araştırma Hastanesi, Kardiyoloji Kliniği, Bursa

Kronik kalp yetmezliği olan hastalarda, sağlıkla ilişkili yaşam kalitesi (health related quality of life; HRQL), önemli bir tedavi hedefidir. ${ }^{[1]}$ Kalp yetmezli$\breve{g i}$ hastalarının fiziksel aktivitelerindeki bozulma derecesi hemodiyaliz hastaları ile, sosyal aktivitelerindeki bozulma derecesi ise depresyon hastaları ile benzerdir. ${ }^{[2,3]}$ Hastaların, yaşam kalitesi algıları, gelecekteki morbidite ve mortalite riskinin de belirleyicisidir. ${ }^{[4,5]}$

Kalp yetmezliği tedavi kılavuzlarında önerilen ilaçların kanıtlanmış mortalite kazancına rağmen, bu tedavilerin yaşam kalitesi üzerine etkisi net olarak ortaya konulmamıştır. $\beta$-blokerler, HRQL de belirgin bir iyileşme sağlamazken, anjiotensin dönüştürücü enzim inhibitörleri (ACE-I) ve anjiotensin reseptör blokörleri (ARB) ile ilgili çalışmalarda ise çelişkili sonuçlar elde edilmiştir. ${ }^{[6,7]}$

PARADIGM-HF çalışmasında, düşük ejeksiyon fraksiyonlu (EF) kalp yetmezlikli (DEF-KY) hastalarda, enalapril ile karşılaştırılan sakubitril/valsartan kombinasyon tedavisinin, kardiyovasküler mortalite, kalp yetmezliği ile ilişkili hastaneye yatış ve tüm nedenli ölümlerde anlamlı azalmaya yol açtı̆̆ı, hayatta kalan hastalarda ise genel yaşam kalitesinde iyileşme sağladığı gösterilmiştir. Kansas City Kardiyomiyopati Anketi (Kansas City Cardiomyopathy Questionnaire; KCCQ) aracılığ PARADIGM-HF çalışmasının ikincil analizlerinde geniş şekilde yer bulmuştur. ${ }^{[8,9]}$

KCCQ anketi, kalp yetmezliği için doğrulanmış, yaygın olarak kullanılan, 23 maddeli, hastanın kendi kendine uyguladığı hastalığa özgü bir yaşam kalite anketidir. ${ }^{[10]}$ KCCQ anketi ile hastalardan, bazı aktiviteleri yaparken kalp yetmezliği semptomları nedeniyle yaşadıkları kısıtlamayı, 0-100 puan arasında puanlamaları istenmektedir. " 0 " puan ciddi kısitlamay1, "100" puan ise hiç kısıtlama olmamasını tanımlamaktadır. Aktivite olarak hastaların, 10 başlık halinde, kendi kendine giyinme, banyo yapma, düz yolda yürüme, bahçe işleri yapabilme, merdiven çıkma, koşma, hobilerini gerçekleştirme, ev işlerini yapabilme, arkadaş ve akraba ziyaretleri, cinsel ilişkideki etkilenme düzeyi sorgulanmaktadır. PARADIGM-HF çalışmasında hastalar randomizasyon ziyaretinde başlangıç HRQL değerlendirmelerini, takipte ise 4. ay, 8. ay, 12 . ay, 24 . ay ve 36 . aylarda veya son vizitte nihai HQRL değerlendirmelerini tamamlamıştır. Sakubitril/ valsartan'ın KCCQ anketi ile zamanlaması önceden belirlendiği şekilde 8 . ayda ve sonrasında, yaşam kalitesi üzerine iyileştirici etkisi, ilişkili biyobelirteçler ve klinik sonuçlar araştırıldı. Çalışmaya alınan 8399 hastanın 7618'i (\%90.7) başlangıçta ve 6881 hasta (\%90) 8.ayda takip KCCQ değerlendirmesini tamamladi. Yaş ortalaması 64 olan bu hastaların \%78.6'sı erkeklerden oluşmaktaydı. Çalışma başlangıcında, koşma ve cinsel ilişkiler en yüksek kısıtlanmaya işaret eden en düşük ortalama puanlara sahipken, kendi kendine giyinmek ve duş almak ise en az kısıtlamayı işaret eden en yüksek ortalama puana sahipti.

Hastaların başlangıçta sahip oldukları ileri yaş, kadın cinsiyet, daha yüksek vücut kitle indeksi, daha kötü NYHA sınıfı, daha yüksek NT-pro BNP seviyesi ve eşlik eden hastalıkların varlığı gibi birçok klinik faktör, fiziksel ve sosyal aktivitelerde daha fazla sınırlama ile ilişkili bulundu. Bu faktörler için düzeltme yapıldıktan sonra, sakubitril/valsartan kullanımı, 8. ay sonunda, bu hastalarda fiziksel ve sosyal aktivite skorundaki iyileşme konusunda bağımsız bir belirleyici faktör olarak tespit edilmiştir $(\mathrm{p}<0.001)$. Bununla birlikte HRQL iyileşmesinin, NT-proBNP düzeylerindeki azalma ve hemodinamik iyileşme ile korele olduğu ve bunun da, sonraki ölüm ve kalp yetmezliği sonuçlarıyla ilişkili olduğu tespit edilmiştir. Sekizinci ay vizitinde fiziksel ve sosyal aktivite skorundaki iyileşme, sakubitril/valsartan alan grupta, yaş ve tedavi etkisine bakıldığında, 9 yıllık gençleşme ile eşdeğer düzeydeydi (\%95 CI, 4-13 y1l) (Şekil 1). Yani sakubitril/ valsartan alan hastalar enalapril alan hastaların 9 yaş daha genç olanları ile aynı yaşam kalitesine sahipti. 


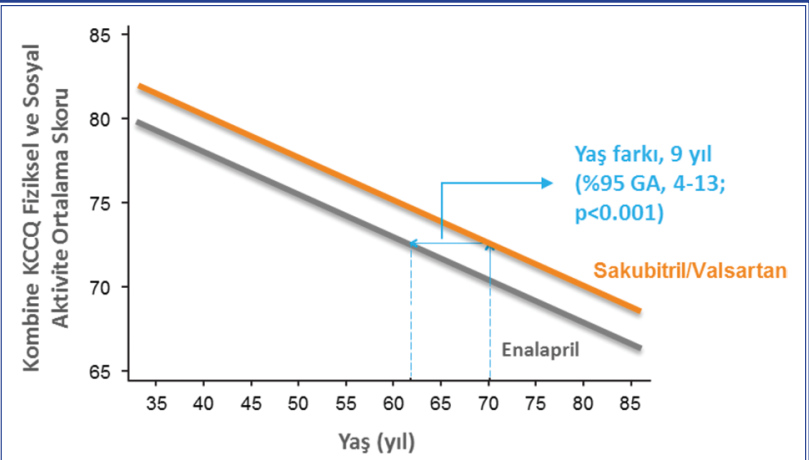

Şekil 1. Sekiz aylık takipte düzeltilmemiş yaş eşdeğerliği analizi. ${ }^{[7]}$

Sekizinci ayda sakubitril/valsartan ile en büyük gelişme cinsel ilişkide (düzeltilmiş değişim skoru far$\mathrm{k} 1,2.72 ; \mathrm{p}=0.002$ ) ve ev işlerinde (düzeltilmiş değişim skoru fark1, 2.35; $\mathrm{p}<0.001)$ tespit edildi. Otuz altı ay sonundaki analizlerde, sakubitril/valsartan, kendi başına giyinmek dışındaki tüm aktivitelerde önemli ölçüde daha fazla iyileşme ile ilişkiliydi. Sakubitril/ valsartan'ın cinsel işlev üzerinde doğrudan bir etkisi olduğuna dair herhangi bir kanıt yoktur ve bu bulgu genel sağlık için bir gösterge olabilir. PARADIGMHF çalışmasında erektil disfonksiyon ile ilgili bir veri toplanmamış ve az sayıda hastanın bu nedenle ilaç kullandığ 1 belirtilmiştir. Ayrıca, hastaların medeni durumları ve cinsel partnerleri ile ilgili bilgi verilmemiştir. Bununla birlikte, kadın cinsel uyarılma bozukluğu tedavisinde, daha önceden nötral endopeptidaz inhibisyonu önerilmiş olması bu alanda da etkisi olabileceğine dair ip ucu olabilir. ${ }^{[11]}$ Dolayısı ile bu alanda gözlenen iyileşmenin mekanizması net değildir. Ancak bu konuyu direkt olarak hedefleyen, kronik DEFKY'si ve hafif-orta düzeyde erektil disfonksiyonu olan erkek hastalarda enalapril tedavisini sakubitril/ valsartanla 3 aylık sürede erektil fonksiyon skor değişimi açısından kıyaslayan CONFIDENCE HF çalışması planlanmıştır. Bu çalışmadan gelecek sonuçlar konuya açıklık getirecektir. Ayrıca PARADIGM HF çalışmasında, 8 ay boyunca kombine fiziksel ve sosyal aktivitedeki iyileşme, azalmış birincil sonlanım noktasındaki risk (kardiyovasküler ölüm veya ilk kalp yetmezliği ile hastaneye yatış) ile ilişkili bulunmuştur. Ancak cinsiyet ile sakubitril/valsartan'ın fiziksel ve sosyal aktiviteler üzerindeki etkisi arasında bir ilişki saptanmamıştır.
Sonuç olarak DEF-KY hastalarında, sakubitril/ valsartan, enalapril ile karşılaştırıldı ğında, en belirgin yanıtı cinsel ilişkide olmak üzere, hastaların fiziksel ve sosyal aktivitelerindeki sınırlamalarını önemli ölçüde iyileştirmiştir. PARADIGM-HF çalışmasında elde edilen HRQL iyileşmesi, kardiyak resenkronizasyon (CRT) tedavisi ile gözlenen HRQL iyileşmesi ile benzer ölçüde bulunmuştur. ${ }^{[12]} \mathrm{Bu}$ çalışmada sakubitril/valsartan, enalaprile göre 9 yıllık gençleşme hissine denk gelen yaşam kalitesinde artışa yol açmıştır.

\section{Kaynaklar}

1. Lewis EF. Assessing the impact of heart failure therapeutics on quality of life and functional capacity. Curr Treat Options Cardiovasc Med 2013;15:425-36.

2. Juenger J, Schellberg D, Kraemer S, Haunstetter A, Zugck C, Herzog $\mathrm{W}$, et al. Health related quality of life in patients with congestive heart failure: comparison with other chronic diseases and relation to functional variables. Heart 2002;87:235-41.

3. Hobbs FD, Kenkre JE, Roalfe AK, Davis RC, Hare R, Davies MK. Impact of heart failure and left ventricular systolic dysfunction on quality of life: across-sectional study comparing common chronic cardiac and medical disorders and are presentative adult population. Eur Heart J 2002;23:1867-76.

4. Soto GE, Jones P, Weintraub WS, Krumholz HM, Spertus JA. Prognostic value of health status in patients with heart failure after acute myocardial infarction. Circulation. 2004;110:546-51.

5. Ekman I, Chassany O, Komajda M, Böhm M, Borer JS, Ford I, et al. Heart rate reduction with ivabradine and health related quality of life in patients with chronic heart failure: results from the SHIFT study. Eur Heart J 2011;32:2395-404.

6. Dobre D, van Jaarsveld CH, deJongste MJ, Haaijer Ruskamp FM, Ranchor AV. The effect of beta-blocker therapy on quality of life in heart failure patients: a systematic review and meta-analysis. Pharmacoepidemiol Drug Saf 2007;16:152-9.

7. Lewis EF. Still at the drawing board: improving quality of life in heart failure. Circ Heart Fail 2012;5:137-9.

8. Lewis EF, Claggett BL, McMurray JJV, Packer M, Lefkowitz MP, Rouleau JL, et al. Health-Related Quality of Life Outcomes in PARADIGM-HF. Circ Heart Fail 2017;10:e003430.

9. Chandra A, Lewis EF, Claggett BL, Desai AS, Packer M, Zile MR, et al. Effects of Sacubitril/Valsartan on Physical and Social Activity Limitations in Patients With Heart Failure: A Secondary Analysis of the PARADIGM-HF Trial. JAMA Cardiol 2018;3:498-505.

10. Green CP, Porter CB, Bresnahan DR, Spertus JA. Development and evaluation of the Kansas City Cardiomyopathy Questionnaire: a new health status measure for heart failure. J Am Coll Cardiol 2000;35:1245-55.

11. Pryde DC, Cook AS, Burring DJ, Jones LH, Foll S, Platts MY, et al. Novel selective inhibitors of neutral endopeptidase for the treatment of female sexual arousal disorder. Bioorg Med Chem 2007;15:142-59.

12. Veazie PJ, Noyes K, Li Q, Hall WJ, Buttaccio A, Thevenet-Morrison $\mathrm{K}$, Moss AJ. Cardiac resynchronization and quality of life in patients with minimally symptomatic heart failure. J Am Coll Cardiol 2012;60:1940-4. 